\title{
Cerebral abscess as an unusual complication of coil embolization in a dural arteriovenous fistula
}

\author{
Adnan Abd. Rahman Zurin, M.D., M.S., Satoshi Ushikoshi, M.D., Kiyohiro Houkin, M.D., Yoichi \\ Kikuchi, M.D., Hiroshi Abe, M.D., and Hisatoshi Saitoh, M.D.
}

Departments of Neurosurgery and Radiology, Hokkaido University School of Medicine, Sapporo, Japan; Azabu Neurosurgical Hospital, Sapporo, Japan; and Division of Neurosurgery, Faculty of Medicine, University Kebangsaan Malaysia, Kuala Lumpur, Malaysia

This 63-year-old man presented with a right temporoparietal cortical infarction. A dural arteriovenous fistula involving the right transverse sinus was diagnosed on cerebral angiography. Transvenous embolization using detachable coils was performed; however, postembolization angiograms demonstrated retrograde filling of a cortical draining vein that was not seen on initial angiography. The patient subsequently developed a cerebral abscess in the region of the previous cortical infarction 2 months after the embolization. The abscess was successfully treated with drainage and antibiotic therapy. The authors report this case to illustrate an unusual complication associated with this procedure and the possible contribution of the cortical draining vein in the pathogenesis of the cerebral abscess.

Key Words * cerebral abscess * brain infarction * dural arteriovenous fistula * transvenous embolization

Dural arteriovenous fistulas (AVFs) comprise a nidus of arteriovenous shunting within the dura mater. In most cases this nidus is located near a dural sinus that may become narrowed or obstructed in the process of nidus formation.[1] Dural AVFs represent 10 to $15 \%$ of all intracranial vascular malformations. They usually occur in the region of the transverse, sigmoid, and cavernous sinuses but may be found in any dural structure. $[2,3,13,16]$

Arterial supply is obtained from dural arteries and from pachymeningeal branches of cerebral arteries, whereas venous drainage occurs via the dural sinus and/or other dural and leptomeningeal venous channels. Retrograde cortical venous drainage is often tortuous, variceal, or frankly aneurysmal.[1] These cortical draining veins are often the source of complications arising from this condition.[1,10,12,15,24] We report an unusual case of a dural AVF that was treated with coil embolization via the transvenous (transjugular) route. The patient developed a cerebral abscess after the emergence of a cortical draining vein postembolization.

\section{CASE REPORT}

This 63-year-old man presented in June 1995 with gradual weakness of the left upper and lower extremities. He also complained of constant, debilitating tinnitus in the right ear. His medical records 
showed that he was diabetic and receiving soluble insulin injections, had previously suffered angina pectoris, and was being treated with nitrates. His family history was noncontributory.

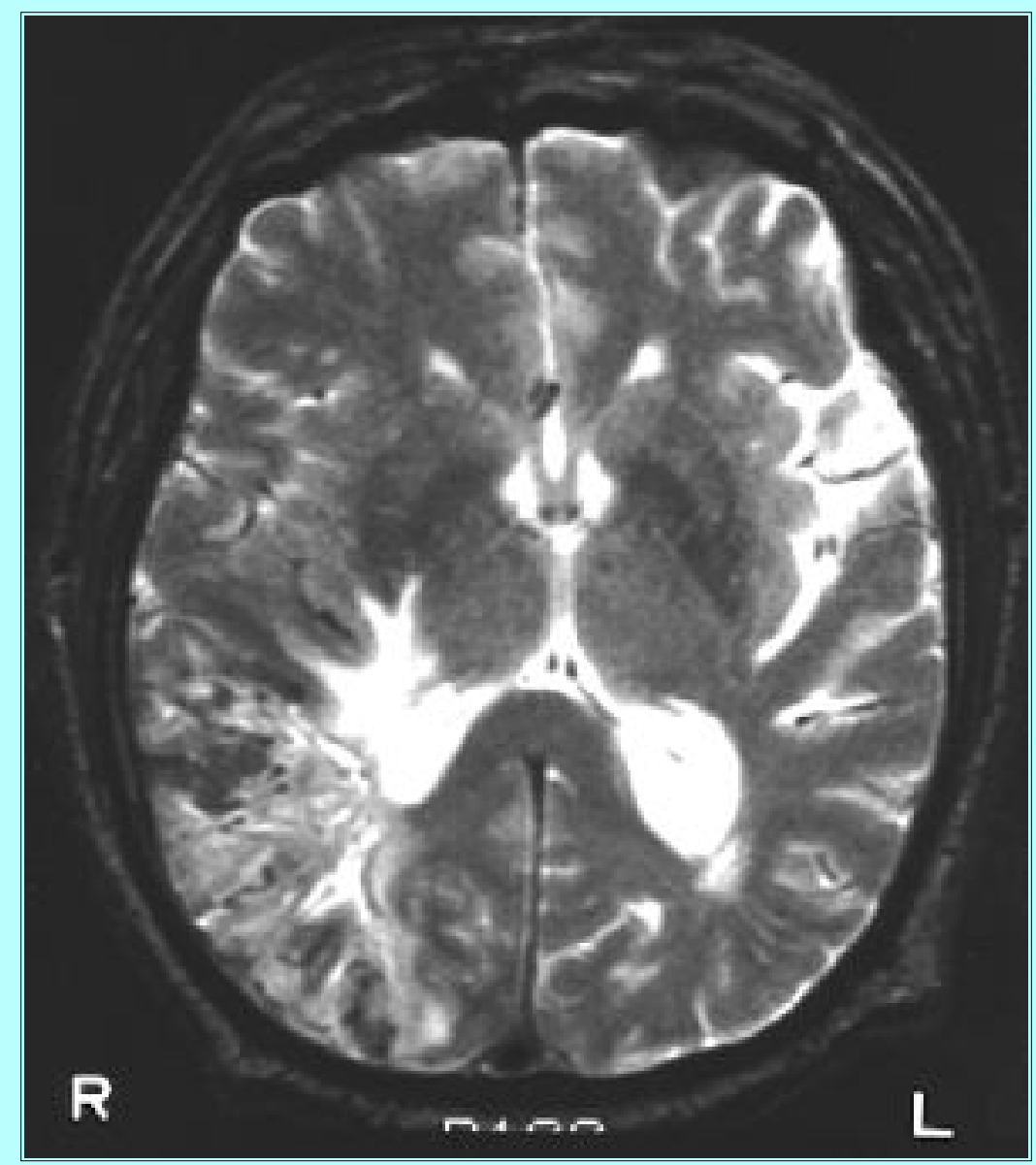

Fig. 1. Axial $\mathrm{T}_{2}$-weighted $\mathrm{MR}$ image showing a hyperintense lesion in the right posterior temporal lobe extending to the parietal lobe.

Examination. Neurological examination revealed a mild left hemiparesis associated with brisk reflexes and an upgoing plantar response. He was also found to have left hemianopsia. Magnetic resonance (MR) imaging showed cortical infarction of the right posterior temporal region extending to the right parietal lobe (Fig. 1). Cerebral angiography demonstrated a dural AVF in the right transverse-sigmoid sinus with drainage into the ipsilateral internal jugular vein (IJV) and the contralateral transverse-sigmoid sinus (Fig. 2 left). No retrograde reflux of the shunt flow into cortical veins could be visualized. The late phase of selective right carotid angiography revealed antegrade filling of the right temporal cortical vein (vein of Labbé) and poor filling of the right parietal cortical vein (Fig. 2 right). Vertebral angiography revealed no involvement of the pial arteries in this dural AVF or retrograde filling of the cortical venous system of the posterior fossa. 


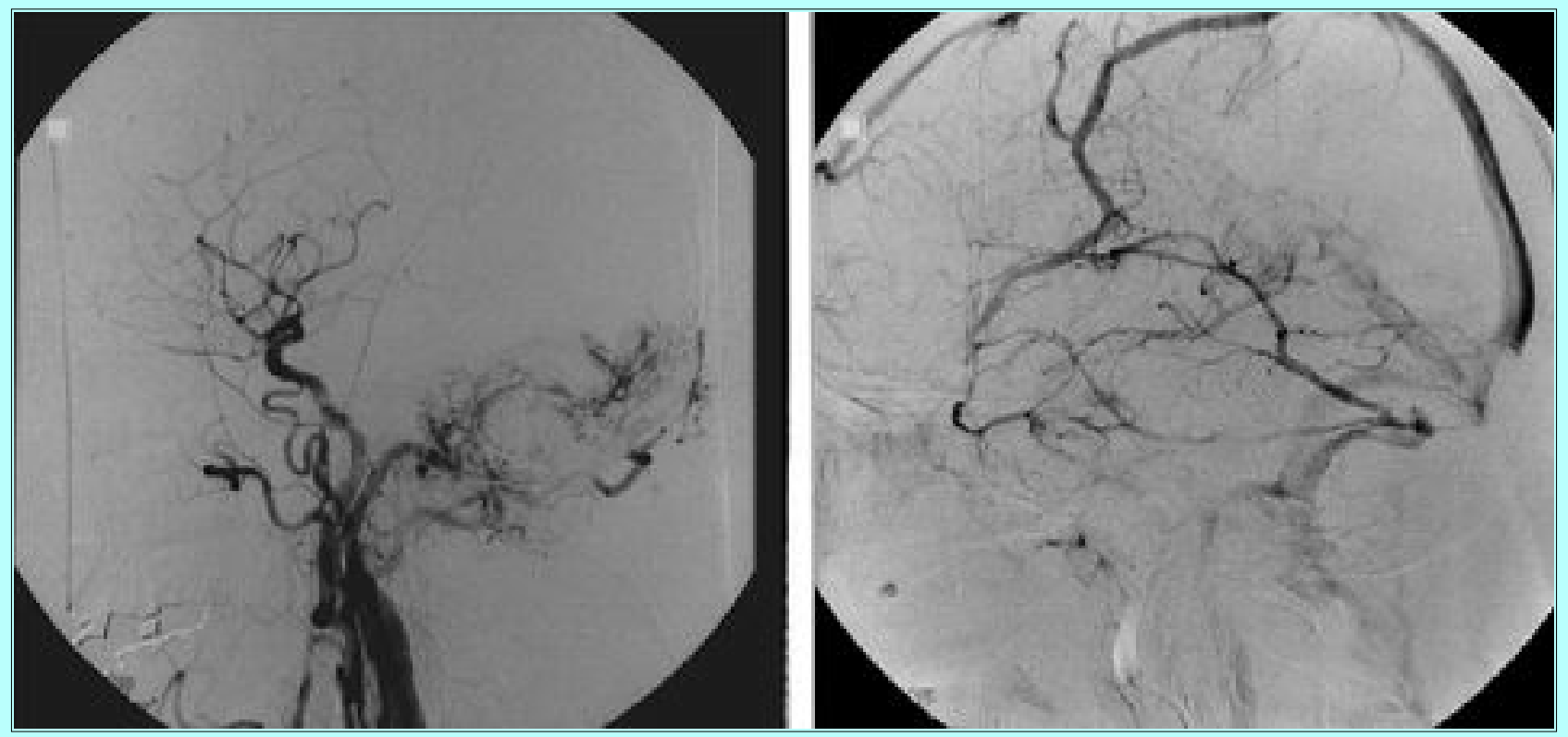

Fig. 2. Left: Right common carotid artery angiogram (lateral view) demonstrating the dural AVF involving the transverse-sigmoid sinus with venous drainage into the ipsilateral IJV and contralateral transverse-sigmoid sinus. Note the paucity of vessels in the right parietal region, which corresponds to the area of infarction. Right: Late venous phase of the selective right carotid angiogram. Note the poor filling of the venous system in the right parietal region and antegrade filling of the cortical vein of Labbé.

First Operation and Outcome. Transvenous embolization was planned to reduce the shunt flow while preserving the antegrade flow of the vein of Labbé. Embolization was subsequently performed via the right IJV by means of transfemoral venous access. Embolization was achieved with the use of multiple pieces of interlocking detachable coils (Target Therapeutics, Fremont, CA). Postembolization angiograms showed a significant reduction in shunt flow. However, they also revealed retrograde filling of a cortical vein (Fig. 3). The patient was scheduled for repeated embolization but he declined further treatment and was subsequently discharged with marked clinical improvement.
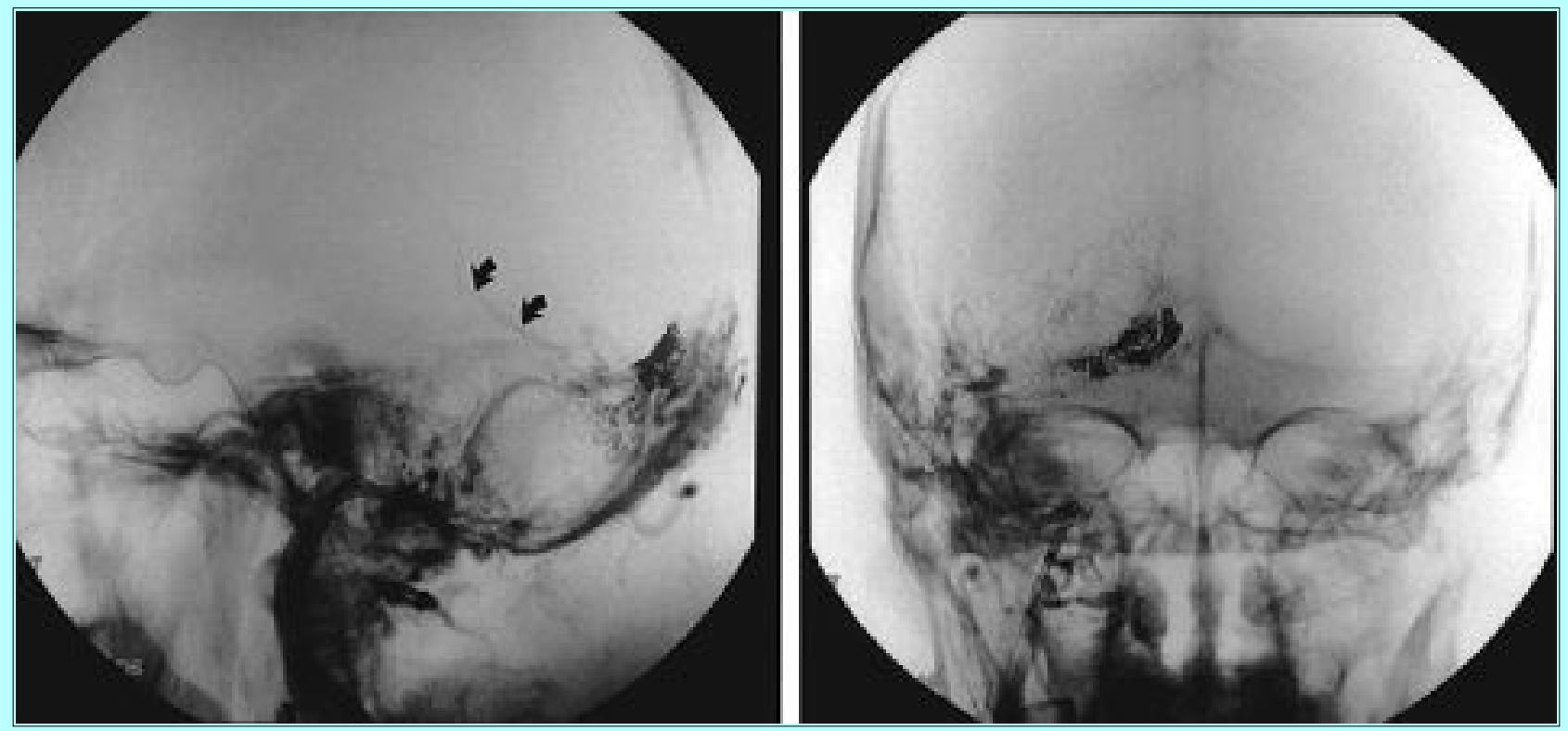

Fig. 3. Angiogram obtained postembolization illustrating the location of the coils and the patency of the transverse sinus, in lateral (left) and anteroposterior (right) projections. A 
retrograde filling of cortical vein can be seen faintly (arrows) in the lateral view.

Second Admission. One month later the patient was readmitted to the hospital with a 1-week history of fever associated with headaches. Physical examination showed no recurrence of the initial problem of left hemiparesis or hemianopsia. A multiloculated cerebral abscess in the right posterior temporal and parietal region was demonstrated on emergency MR images (Fig.4).

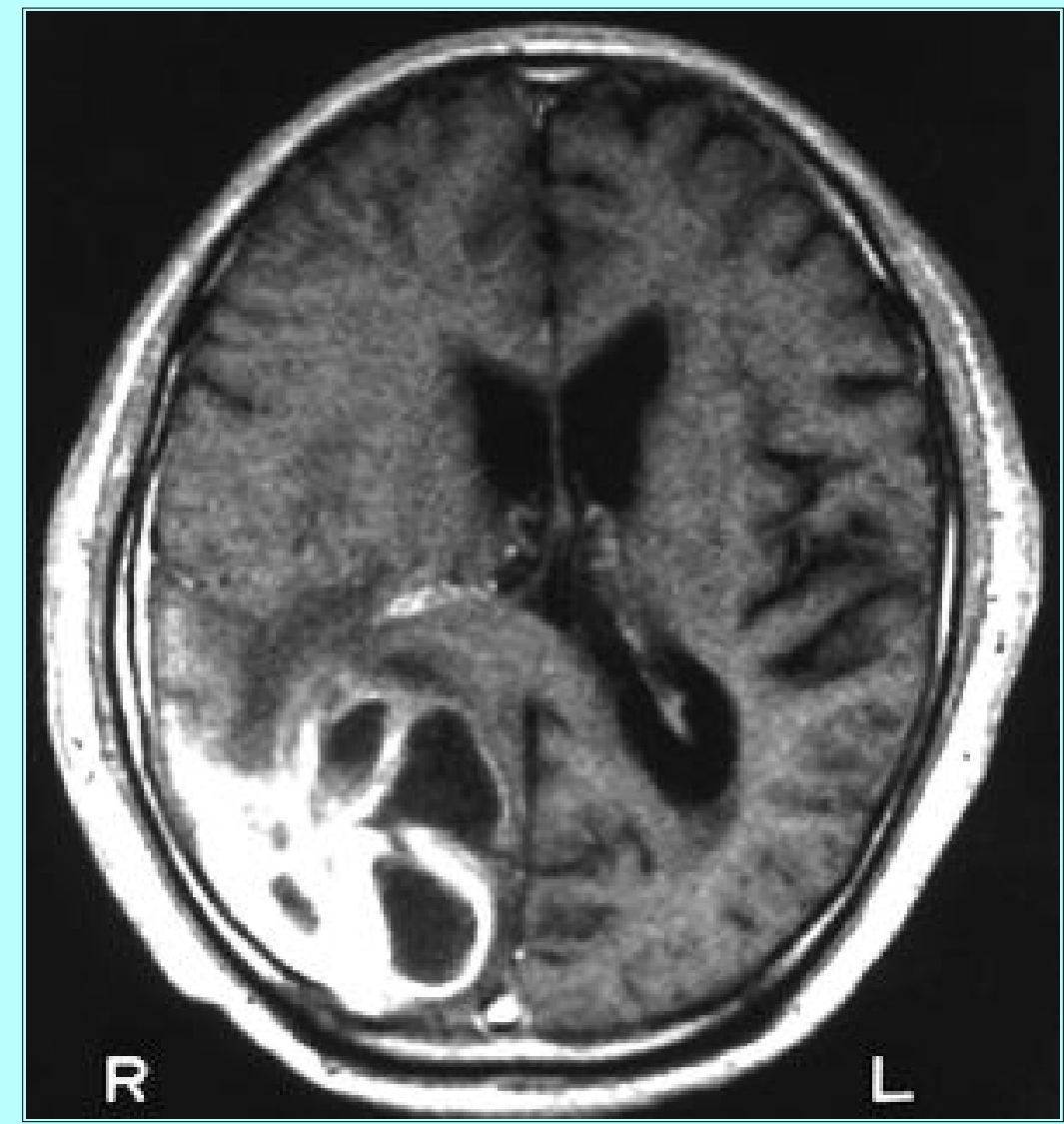

Fig. 4. Axial contrast-enhanced $\mathrm{T}_{1}$-weighted $\mathrm{MR}$ image obtained during the patient's second admission showing a multiloculated lesion with ring enhancement in the right posterior parietal lobe.

A course of antibiotic drugs was initiated and the abscess was successfully drained via a burr hole. Staphylococcus aureus grew on bacterial culture of the pus and antibiotic therapy was continued for a period of 2 months. A repeated MR image obtained after completion of the therapy showed complete resolution of the cerebral abscess. Digital subtraction angiography clearly demonstrated retrograde filling of the cortical vein draining the fistula (Fig. 5). The patient declined further embolization although he remains at risk for hemorrhage because of the residual AVF. He achieved gradual recovery of his limb function but on discharge was noted to have significant intellectual deterioration.

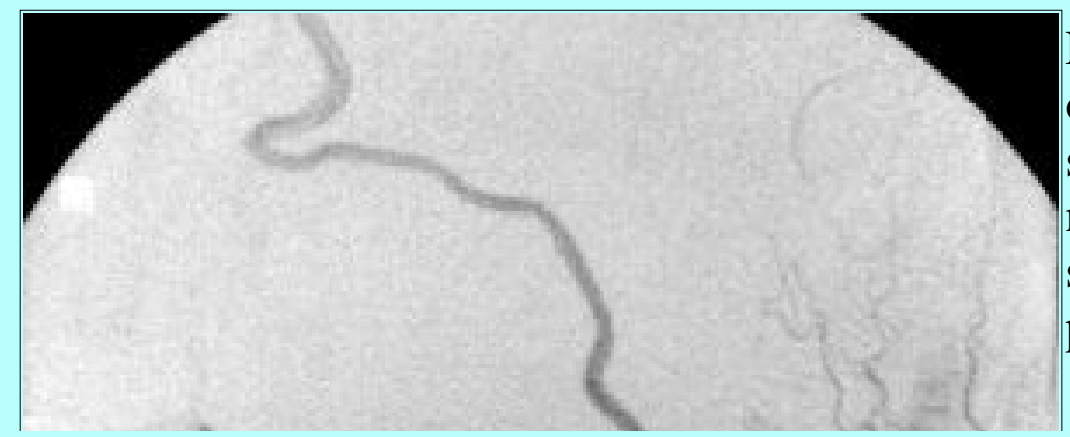

Fig. 5. Digital subtraction angiogram obtained during the second admission clearly showing a cortical draining vein and near-total occlusion of the right transverse sinus. Note the proximity of the vein to the previous area of cortical infarction. 


\section{DISCUSSION}

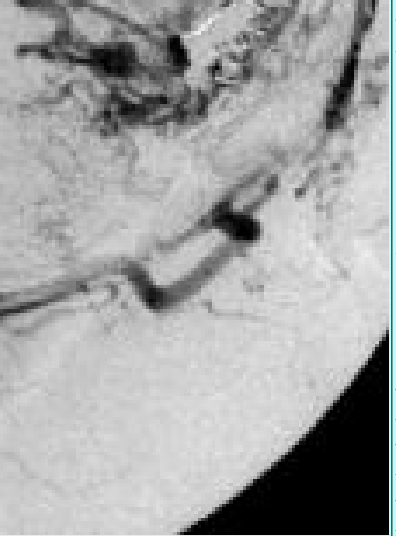

Evidence indicates that dural AVF is acquired after dural sinus thrombosis.[5,18] Although spontaneous closure[4] as well as closure following diagnostic angiography[7,8,20] have been reported, the majority of AVFs remain patent.

Clinical signs and symptoms may include bruit, headache, dementia, neurological deficits, and hemorrhage.[15] Various treatment techniques have been developed as more has been discovered about the natural history of this condition. Ligation of feeding arteries has been a failure as a form of treatment because of the development of extensive collateral vessels that keep the fistula patent.[21,22] Direct surgical treatment of the involved dural sinus is an accepted mode of management, often resulting in the loss of the involved dura. However, the extensive vascularity of the lesion results in substantial blood loss during surgical resection.[30] More recently, transarterial[25,29] and transvenous[14,15] embolization have been shown to be good alternative treatments for dural fistulas.

Transvenous embolization of dural AVFs was first described by Mullan[28] in 1979 in a case involving the cavernous sinus. Since then various types of embolic material, both liquid and particulate, have been used for this purpose. The transvenous approach has several distinct advantages over embolization via the arterial route. There is less likelihood that emboli will pass through branching vessels proximal to the dural AVF and lodge in normal capillary beds. Furthermore, feeding vessels are not occluded and any fistula remaining after the initial embolization can be studied angiographically. If necessary, a repeated embolization may be performed.[3]

Detachable microcoils made from platinum or steel have the advantage of thrombogenicity, and if properly sized, they remain within the sinus, producing thrombosis. However, there are complications inherent to this treatment technique. If inadequate numbers of coils are placed within a segment of the diseased sinus having cortical venous drainage, diversion of arterialized blood to these veins could occur and result in neurological deficit, hemorrhage, or venous infarction. This complication can be avoided by placing adequate numbers of coils within the sinus at the origin of these veins. If the embolic materials occlude cortical veins not exposed to high venous pressure in adjacent dural sinus, venous infarction may occur. Placement of the emboli only within the diseased segment can prevent this potential complication.[15] Patients who have cortical venous drainage away from the sinus are at high risk to develop hemorrhage and therefore require definitive treatment.[1,12,15,24]

A review of the literature showed a number of reports illustrating the development of cerebral abscess in previously infarcted brain tissue. $[6,19,23]$ The authors were in agreement regarding the pathophysiology of this phenomenon. Intact brain is quite resistant to infection. This fact was noted as early as 1934 when Groff[11] injected bacteria into the carotid artery and directly into the brains of cats but ultimately failed to induce the formation of a cerebral abscess. Subsequent experimental models of brain abscess have indicated that alteration of the brain by ischemia or necrosis from other causes is a prerequisite for abscess formation.[9,17,26,27] It is believed that the blood-brain barrier is broken and the local immunological system guarding against bacteria may be weakened when the brain is damaged by ischemia.[6,19] Infection could occur in areas of cerebral infarction even with transient bacteremia and is 
more likely when an infective source is present.[19,23]

In our case, the patient developed the cortical draining vein only after the embolization, suggesting incomplete obliteration of the diseased sinus segment. That this particular draining vein courses through the previously infarcted region of the brain raises the possibility of organisms being transmitted from the partially embolized sinus to the susceptible area of damaged brain. This, coupled with the fact that the patient has diabetes, increases the likelihood of infection occurring in the aforementioned setting.

This case report illustrates an unusual complication arising from transvenous embolization of a dural AVF by means of coils and emphasizes the need for adequate and complete embolization of the diseased sinus. We also suggest the use of prophylactic antibiotic drugs during the course of these endovascular procedures, particularly in certain selected high-risk patients such as this case. In general, these endovascular treatments take a long time and this procedure is not always strictly aseptic. Therefore, patients with diabetes or with some immunological compromise should receive prophylactic antibiotic medications.

\section{References}

1. Awad IA, Little JR, Akrawi WP, et al: Intracranial dural arteriovenous malformations: factors predisposing to an aggressive neurological course. J Neurosurg 72:839-850, 1990

2. Barnwell SL, Halbach VV, Dowd CF, et al: Dural arteriovenous fistulas involving the petrosal sinus : angiographic findings in six patients. AJNR 11:511-516, 1990

3. Barnwell SL, Halbach VV, Higashida RT, et al: Complex dural arteriovenous fistulas. Results of combined endovascular and neurosurgical treatment in 16 patients. J Neurosurg 71:352-358, 1989

4. Bitoh S, Sasaki S: Spontaneous cure of dural arteriovenous malformation of the posterior fossa. Surg Neurol 12:111-114, 1979

5. Chaudhary MY, Sachdev VP, Cho SH, et al: Dural arteriovenous malformation of the major venous sinuses: an acquired lesion. AJNR 3:13-19, 1982

6. Chen ST, Tang LM, Ro LS: Brain abscess as a complication of stroke. Stroke 26:696-698, 1995

7. Conforti P: Spontaneous disappearance of cerebral arteriovenous angioma. Case Report. J Neurosurg 34:432-434, 1971

8. Eisenman JI, Alekoumbides A, Pribram H: Spontaneous thrombosis of vascular malformations of the brain. Acta Radiol Diagn 13:77-85, 1972

9. Falconer M, McFarlan A, Russel D: Experimental brain abscess in the rabbit. Br J Surg 30:245-260, 1943

10. Gobin YP, Houdart E, Rogopoulos A, et al: Percutaneous transvenous embolization through the thrombosed sinus in transverse sinus dural fistula. AJNR 14:1102-1105, 1993

11. Groff A: Experimental production of abscess of the brain in cats. Arch Neurol Psychiatry 31:199-204, 1934

12. Halbach VV, Higashida RT, Hieshima GB, et al: Carotid cavernous fistulae: indications for urgent 
treatment. AJR 149:587-593, 1987

13. Halbach VV, Higashida RT, Hieshima GB, et al: Dural fistulas involving the transverse and sigmoid sinuses: results of treatment in 28 patients. Radiology 163:443-447, 1987

14. Halbach VV, Higashida RT, Hieshima GB, et al: Transvenous embolization of dural fistulas involving the cavernous sinus. AJNR 10:377-383, 1989

15. Halbach VV, Higashida RT, Hieshima GB, et al: Transvenous embolization of dural fistulas involving the transverse and sigmoid sinuses. AJNR 10:385-392, 1989

16. Halbach VV, Higashida RT, Hieshima GB, et al: Treatment of dural fistulas involving the deep cerebral venous system. AJNR 10:393-399, 1989

17. Hassler O, Fosgren A: Experimental abscess in brain and subcutis. Acta Pathol Microbiol Scand 62:59-67, 1964

18. Houser OW, Campbell JK, Campbell RJ, et al: Arteriovenous malformation affecting the transverse dural sinus--an acquired lesion. Mayo Clin Proc 54:651-661, 1979

19. Ichimi K, Ishiguri H, Kida Y, et al: [Brain abscess following cerebral infarction: a case report.] No Shinkei Geka 17:381-385, 1989 (Jpn)

20. Kataoka K, Taneda M: Angiographic disappearance of multiple dural arteriovenous malformations. Case report. J Neurosurg 60:1275-1278, 1984

21. Kosnik EJ, Hunt WE, Miller CA: Dural arteriovenous malformations. J Neurosurg 40:322-329, 1974

22. Kühner A, Krastel A, Stoll W: Arteriovenous malformations of the transverse dural sinus. J Neurosurg 45:12-19, 1976

23. Kurlan R, Griggs RC: Cyanotic congenital heart disease with suspected stroke. Should all patients receive antibiotics? Arch Neurol 40:209-212, 1983

24. Lasjaunias $\mathrm{P}$, Chu M, Ter Brugge K, et al: Neurological manifestations of intracranial dural arteriovenous malformations. J Neurosurg 64:724-730, 1986

25. Lasjaunias P, Halimi PH, Lopez-Ibor L, et al: Traitement endovasculaire des malformations vasculaires durales (MVD) pures spontanées: revue de 23 cas explorés et traités entre mai 1980 et octobre 1983. Neurochirurgie 30:207-223, 1983

26. Long WD, Meacham WF: Experimental method for producing brain abscesses in dogs with evaluation of the effect of dexamethasone and antibiotic therapy on pathogenesis of intracerebral abscesses. Surg Forum 19:437-438, 1968

27. Molinari GF, Smith L, Goldstein MN, et al: Brain abscess from septic cerebral embolism: an experimental model. Neurology 23:1205-1210, 1973

28. Mullan S: Treatment of carotid-cavernous fistulas by cavernous sinus occlusion. J Neurosurg 50:131-144, 1979 
29. Picard L, Bracard S, Mallet J, et al: Spontaneous dural arteriovenous fistulas. Semin Intervent Radiol 4:219-240, 1987

30. Sundt TM Jr, Piepgras DG: The surgical approach to arteriovenous malformations of the lateral and sigmoid dural sinuses. J Neurosurg 59:32-39, 1983

Manuscript received February 17, 1997.

Accepted in final form March 17, 1997.

This work was supported in part by Core University System Exchange Program under the Japan Society for the Promotion of Science, coordinated by the University of Tokyo Faculty of Medicine and Universiti Sains Malaysia, School of Medical Sciences.

Address reprint requests to: Kiyohiro Houkin, M.D., Department of Neurosurgery, Hokkaido University School of Medicine, N-15, W-7, Sapporo, 060, Japan. email: khokin@ med.hokudai.ac.jp. 